\title{
An analysis of leadership characteristics of search and rescue volunteers
}

\author{
Burak GURER, Ilhan ADILOGULLARI² \\ ${ }^{1}$ School of Physical Education and Sport, Gaziantep University, Gaziantep, Turkey. \\ ${ }^{2}$ School of Physical Education and Sport, Çanakkale Onsekiz Mart University, Çanakkale, Turkey. \\ Address Correspondence to B. Gürer, burakgurer27@gmail.com
}

\begin{abstract}
The main purpose of this study was to analyze the leadership behaviors of volunteer leaders in search and rescue field. 118 volunteer leaders attended this study on a volunteer basis. Data were collected through the use of the Multifactor Leadership Questionnaire, which was developed by Bass \& Avolio (1985) and adapted into Turkish by Demir \& Okan. 20 items were used to measure transformational leadership while 16 of them were applied for transactional leadership. One Way Anova and T-test statistics were used in order to evaluate the data. Consequently, it was observed that intellectual motivation and individualized consideration of the participants change according to educational variables. Management-by-exception in its passive form indicated a remarkable difference in terms of gender. It is also found that leaders are expected to motivate the members mentally in order to increase the level of motivation. High level of the individual knowledge of a leader is pointed out as an important issue by the participants. Although there is an autocratic structure in search and rescue, a good leadermember relationship is thought to provide certain advantages. Accordingly, the leader who could promote trust among the members of the team is perceived as a sophisticated leader.
\end{abstract}

Key Words: Leadership, search and rescue, volunteer.

\section{INTRODUCTION}

Search and rescue operations have become more important due to the increase in disasters. In a world where urbanization is increased, individuals prefer to spend more time outdoors where they have an opportunity to feel nature. The demand for extreme sports, where nature itself is the resource, also increases as a result of the individuals' preferences (14). Also, there has been a remarkable rise in mountain tourism in recent years. As they become much more popular for the masses who are in search for alternative tourism, extreme and mountain sports may cause life-threatening consequences for unconscious individuals who do not follow regulations (26). The news related to accidents and disasters in nature reveal the importance of search and rescue operations which is the basis of this research.

There are various activities carried out in nature. These activities adventure sports can be either popular or may contain high-risk factors that require advanced techniques (14). The number of individuals performing extreme sports reveals the shortage of qualified staff that has the capacity to guide in nature. Outdoor leadership means to direct individuals and groups within natural environment by means of various transportation methods. This is a risky type of leadership that demands responsibility (18). The relationship between research and practice related to outdoor leadership are usually gathered around the studies carried out in 1980 (2). Outdoor activities in nature may occasionally cause some accidents. In their research, Wu \& Chang (29) considered accidents and they emphasized not only the significance of risk management but also the leader's ability to make decisions. Wrong decisions may cost lives of people in outdoor activities. From this point of view search, rescue and leadership factors have been appeared to be important.

The leader directs extreme sports activities and determines security strategies. The leader must have professional knowledge, technical skills and also should have the training of first-aid (10). As a consequence of an increase in natural disasters and accidents, effective and immediate search and rescue operations are required. One of the factors that provide efficiency is an experienced and successful 
leader (20). In order to respond to incidents effectively, experienced leaders, trained staff, efficient transportation and logistic on support, appropriate means of communication, operational and guiding regulations to be used in emergency cases should be required (28). In the areas where search and rescue activities are insufficient, administrative tasks appear to be more important. Keeping the limited number of staff ready for search and rescue operations can only be realized by efficient management. Adequate management generates effective search and rescue operations (12). Gürer (9) and indicates the importance of the interaction level among leader and members which increases in emergency cases such as search and rescue operations.

As stated above, leadership is very crucial in search and rescue operations. Leadership is the art of impressing people mentally, physically and emotionally. Leadership can be defined as the process of impressing the group to achieve the determined objectives (6). Search and rescue leaders usually work under risky conditions. The members who work under such conditions know that they risk their lives. These people push their physical and mental limits. By means of their perceptual experience, they create a sense of control for an upcoming chaos environment (17).

The rise in the number of volunteers is essential for AKUT Search and Rescue Association and similar organizations to reinforce their operational capacity. This will provide the chance to intervene in the probable disasters all around the country immediately and also to reduce loss of life and property. Human resource is a great value for voluntary organizations like AKUT. As limited research exists concerning search and rescue operations and leadership in the literature, the outcomes of this research are expected to provide guidance for authorities and administrators. In this respect, the obtained of the behaviours and characteristics of search and rescue leaders are important for present and future studies.

Search and rescue requires an active leader member relationship. This research shows that different leadership styles are observed in search and rescue operations. Search and rescue is risky and stressful situation as a whole. In organizational work units, subordinates become members of an inner group or outer group depending on how well they work with leaders and how well leaders work with them (21). It is thought that the better and stronger the interaction, the more successful the operation. The hierarchical structure is often observed in search and rescue organisations. As long as the balance between leader-member interaction and hierarchical structure is protected, it is thought that effective leadership is observed in operations. In a high quality interaction setting, superiors should establish a closer working relationship with a small subordinate group. In leader-member interaction approach, this relationship is called "internal group" (4). In search and rescue operations especially the ones which require particularly serious technical knowledge and working with small groups is preferred more often. Besides, researchers have noted the importance of the mature partnership phase in leader member interactions. Graen \& Uhl-Bien (1991), stated that in order to have a high quality leader member relationship, a mature partnership phase is required. This phase requires a high level of mutual trust, trust and responsibility (21).

Transformational and transactional leadership, among the contemporary leadership approaches, has been the topic of many researches in recent years. In these approaches the importance of the member leader relationship is stressed. From these perspectives, the leader member interaction approach sets the basis for search and rescue.

\section{MATERIAL \& METOT}

It is known that AKUT volunteers work in different regions of Turkey. As it is hard to reach all of the AKUT volunteers due to time and financial means, the study has several limitations. For that reason, the researchers have tried reach the available AKUT volunteers. 186 questionnaires were delivered in total. 132 returned and 118 of them were evaluated. AKUT Search and Rescue Association work and actively participates in numerous search and rescue activities throughout Turkey. It has members from all parts of the society and they are all volunteers. This voluntary participation creates an abundance of human resource. Therefore, members become candidate leaders after completing the training and gaining through certain experience over time.

\section{Universe and Sample}

The participants in this study were all voluntary members of AKUT Search and Rescue Association, who were active training participants. The participants were also chosen among the members who attend operations. AKUT, as a civil 
organization, is the largest search and rescue association in Turkey. It has branch offices in several provinces. AKUT responds many disasters such as flood, earthquake, mountain, avalanche etc. In this regard AKUT has a significant place in terms of natural disasters. Being composed of entirely volunteer members offers a different importance for this research. Members who attend to periodical trainings could reach the trainer position in time. People who are experienced experts in their fields lead search and rescue operations. The researcher has served as a volunteer trainer at AKUT organization since 2006.

This association is organized in many provinces of Turkey. The population of the study consists of volunteer members who are the members of AKUT. The sample of the study is consisted of the members who are the members of AKUT and has been in the association for five years. These members are at the level of being able to participate in instructor trainings and the questionnaires have been carried out during this training. The study includes descriptive model regarding multifactor leadership characteristics of AKUT volunteers while relational model is used to analyse the relationship between these characteristics with demographic variables. There were 69 male $(58.5 \%)$ and 49 female (41.5\%) respondents. $22(17.9 \%)$ of the respondents are high school graduates, $76(65.2 \%)$ of them have a university degree while $20(16.9 \%)$ of them are post graduates. The age group of 18-25 appears to have the highest rate $28(23.7 \%)$. The percentage of the respondents between 31-35 ages is 22.9 while the age group of 36-40 constitutes a percentage of 22.9. On this basis, it can be said that age distribution has a homogenous structure. The rate of single respondents is 63.6 percent. It is concluded that mostly singles prefer to participate in search and rescue operations.

\section{AKUT Search and Rescue Association}

AKUT admits members on $100 \%$ voluntary basis and tries to reach people at all age groups by its organisations such as AKUT Children Academy, AKUT Sports Club, AKUT Culture and Arts Club, AKUT City Volunteers, AKUT Students Groups, and AKUT Foundation. It raises money with donations and by providing training services to institutions. It is the largest and most comprehensive non-governmental organisation in the field of search and rescue in Turkey. It operates in several fields such as mountain search and rescue, earthquake, flood, missing person and animal rescue. As AKUT is a non-governmental organisation, anyone could be a member of it. According to the participants' interest and curiosity, human resources direct them to units such as communications, logistics, medical support, search and rescue, etc. (9). Then, they begin trainings in the relevant unit and they become involved in the operations as the time progresses. As is well-known, search and rescue includes critical processes. Therefore, leadership becomes prominent in these processes which also include intense relationships. This study aims to investigate leadership characteristics of leaders in search and rescue operations conducted by AKUT Search and Rescue Association.

\section{Data Collection Tool}

In the first part of the survey demographic information was collected to determine the demographic variables of the participants. In the second part, the multifactor leadership scale that was developed by Bass \& Avolio (1) and adapted into Turkish by Demir \& Okan (5) was applied to the participants. The same scale has been used in numerous studies (16). Adjustments have been made in expressions of the scale and used in the research. The scale consisted of 5 point likert-type items, ranging from 1 "totally disagree", 2 “Disagree", 3 "Partially agree", 4 "Agree", 5 "Totally agree". In the scale, 20 items were in the sub-scale of transformational leadership and 16 were in interactional leadership. Among these, items 1 and 8 questioned about the effect of transformational leadership on charisma and the ideal effect, items 912 were about intellectual stimulation, items 13-16 were about individual attention, and items 17-20 were about inspiring leadership. The distribution of the items in interactional leadership is as follows. Items 21-24 were about conditional award sub-scale of interactional leadership, items $25-28$ were about active management by exceptions, items $29-32$ were about passive management by exceptions, and finally items 33-36 were about liberating leadership behaviours.

According to this, sub-dimensions that constitute transformational leadership behaviours have been identified in order to establish leadership modalities in the organization. These subdimensions have been evaluated in four factors. First dimension includes idealized influence and also charisma. Second dimension includes leading by inspiring the followers, third dimension includes intellectual stimulation and finally fourth dimension consists of individualized consideration. The 
dimensions that are measured in terms of transformational leadership behaviors consist of contingent reward, management by exceptionactive, management by exception- passive and releasing leadership sub-dimensions (19). The scale consists of 36 items. Bass \& Avolio evaluated different leadership dimensions by the scale they developed. This scale has been used in several researchers in different countries $(25,27)$. Twenty items for transformational and 16 items for transactional leadership have been used in evaluation. Charisma and idealized influence, inspirational motivation, individualized consideration and inspirational dimensions of transformational leadership were taken into consideration. For the evaluation of transactional leadership, contingent reward, management-byexception (active), management-by-exception (passive) and laissez-faire leadership characteristics were evaluated (27).

\section{Collecting Data}

The data have been collected by the researcher during the training programme held by AKUT between 7-10 November 2013 in Olympos, Antalya. Also, the questionnaire was sent to AKUT units via e-mail. The major part of the survey was collected in Antalya during the training programme. The participants are the volunteers who have actively participated in search and rescue operations for minimum five years. The researcher serves at AKUT Search and Rescue Association as an instructor. Furthermore, he has participated in many operations and rescue missions as a rescue leader. He has participated in search and rescue missions since 1999 Marmara Earthquake and 2011 Earthquake in Ercis, Van. Besides, he has led many technical mountain rescue operations. The data has normal distribution and it is homogenous.

\section{Reliability and Validity Analysis of Data Collection Tool}

Cronbach's Alpha coefficient has been used to measure reliability in general. Reliability is a concept that includes the consistency and validity of all the questions and the homogeneity to measure the formation. The method improved to evaluate the reliability of the tests is defined as reliability analysis and the evaluation of the questions is entitled as question analysis. In the study, Cronbach's Alpha was calculated to be 0.90 . The results were evaluated from two perspectives in terms of reliability (95\%) and significance $(p<0.05$ and $p<0.01)$.

\section{The Evaluation of the Data}

The data collected by multifactor leadership and demographic information questionnaires were analysed and the outcomes were interpreted by means of the statistical package programme (SPSS 16.0). The descriptive statistical parameters such as arithmetic average, standard deviation, frequency and percentage distribution were presented in order to have information about demographic background and the other groups of questions. One Way Anova Test was conducted in order to examine more than two groups. Tukey Test was applied to determine groups that cause diversity.

Abbreviations: MLQ: Multifactor Leadership Questionnaire, TRFL: Transformational Leadership, TRAL: Transactional Leadership, CII: Charisma and Idealized Influence, CR: Contingent Reward, IM: Inspirational Motivation, MBEA: Management-byException (Active), IC: Individualized Consideration, MBEP: Management-by-Exception (Passive), IL: Inspirational Leadership, LFL: LaissezFaire Leadership.

\section{RESULTS}

Table 1. Multifactor leadership survey averages

\begin{tabular}{llll}
\hline & $\mathrm{N}$ & Mean & SD \\
\hline TRFL & 118 & 3.63 & \\
TRAL & 118 & 3.10 & 0.75 \\
CII & 118 & 3.70 & 0.40 \\
IM & 118 & 3.68 & 0.81 \\
IC & 118 & 3.50 & 0.86 \\
IL & 118 & 3.59 & 0.84 \\
CR & 118 & 3.65 & 0.80 \\
MBEA & 118 & 3.83 & 0.77 \\
MBEP & 118 & 2.70 & 0.85 \\
LFL & 118 & 2.24 & 0.58 \\
& & & 0.79 \\
\hline
\end{tabular}


Table 2. Multifactor leadership survey averages of the participants in terms of educational variables.

\begin{tabular}{|c|c|c|c|c|c|c|}
\hline & Education & $\mathrm{N}$ & Mean & $\mathrm{SD}$ & F & $\mathrm{P}$ \\
\hline \multirow[t]{3}{*}{ TRFL } & High School & 22 & 3.80 & 0.82 & & \\
\hline & University & 76 & 3.54 & 0.76 & 1.55 & 0.21 \\
\hline & Post Graduate & 20 & 3.80 & 0.58 & & \\
\hline \multirow[t]{3}{*}{ TRAL } & High School & 22 & 3.11 & 0.44 & & \\
\hline & University & 76 & 3.11 & 0.41 & 0.03 & 0.96 \\
\hline & Post Graduate & 20 & 3.08 & 0.36 & & \\
\hline \multirow[t]{3}{*}{ CII } & High School & 22 & 3.82 & 0.89 & & \\
\hline & University & 76 & 3.63 & 0.82 & 0.74 & 0.47 \\
\hline & Post Graduate & 20 & 3.83 & 0.65 & & \\
\hline \multirow[t]{3}{*}{ IM } & High School & 22 & 3.95 & 0.98 & & \\
\hline & University & 76 & 3.51 & 0.87 & 4.59 & $0.01^{* *}$ \\
\hline & Post Graduate & 20 & 4.05 & 0.45 & & \\
\hline \multirow[t]{3}{*}{ IC } & High School & 22 & 3.68 & 1.04 & & \\
\hline & University & 76 & 3.36 & 0.83 & 3.07 & $0.05^{*}$ \\
\hline & Post Graduate & 20 & 3.82 & 0.53 & & \\
\hline \multirow[t]{3}{*}{ IL } & High School & 22 & 3.72 & 0.83 & & \\
\hline & University & 76 & 3.58 & 0.81 & 0.55 & 0.57 \\
\hline & Post Graduate & 20 & 3.46 & 0.79 & & \\
\hline \multirow[t]{3}{*}{$\mathrm{CR}$} & High School & 22 & 3.85 & 0.75 & & \\
\hline & University & 76 & 3.63 & 0.81 & 1.09 & 0.33 \\
\hline & Post Graduate & 20 & 3.51 & 0.60 & & \\
\hline \multirow[t]{3}{*}{ MBEA } & High School & 22 & 3.88 & 0.99 & & \\
\hline & University & 76 & 3.76 & 0.88 & 0.68 & 0.50 \\
\hline & Post Graduate & 20 & 4.01 & 0.54 & & \\
\hline \multirow[t]{3}{*}{ MBEP } & High School & 22 & 2.47 & 0.66 & & \\
\hline & University & 76 & 2.75 & 0.55 & 2.11 & 0.12 \\
\hline & Post Graduate & 20 & 2.76 & 0.56 & & \\
\hline \multirow[t]{3}{*}{ LFL } & High School & 22 & 2.23 & 1.05 & & \\
\hline & University & 76 & 2.29 & 0.75 & 0.66 & 0.51 \\
\hline & Post Graduate & 20 & 2.06 & 0.61 & & \\
\hline
\end{tabular}

${ }^{*} \mathrm{p}<0.05 ;{ }^{* *} \mathrm{p}<0.01$; There is a significant relation according to the age.

Table 3. Multifactor leadership survey averages of the participants in terms of gender variable.

\begin{tabular}{|c|c|c|c|c|c|c|}
\hline & Gender & $\mathrm{N}$ & Mean & SD & $\mathrm{t}$ & $\mathrm{P}$ \\
\hline \multirow[t]{2}{*}{ TRFL } & Female & 49 & 3.57 & 0.55 & $0 .-89$ & 0.37 \\
\hline & Male & 69 & 3.68 & 0.86 & & \\
\hline \multirow[t]{2}{*}{ TRAL } & Female & 49 & 3.14 & 0.32 & 0.88 & 0.37 \\
\hline & Male & 69 & 3.08 & 0.45 & & \\
\hline \multirow[t]{2}{*}{ CII } & Female & 49 & 3.56 & 0.66 & -1.68 & 0.09 \\
\hline & Male & 69 & 3.80 & 0.89 & & \\
\hline \multirow[t]{2}{*}{ IM } & Female & 49 & 3.71 & 0.57 & 0.32 & 0.74 \\
\hline & Male & 69 & 3.66 & 1.02 & & \\
\hline \multirow[t]{2}{*}{ IC } & Female & 49 & 3.40 & 0.69 & -1.03 & 0.30 \\
\hline & Male & 69 & 3.56 & 0.94 & & \\
\hline \multirow[t]{2}{*}{ IL } & Female & 49 & 3.59 & 0.68 & 0.04 & 0.96 \\
\hline & Male & 69 & 3.59 & 0.89 & & \\
\hline \multirow[t]{2}{*}{ CR } & Female & 49 & 3.75 & 0.58 & 1.30 & 0.19 \\
\hline & Male & 69 & 3.57 & 0.88 & & \\
\hline \multirow[t]{2}{*}{ MBEA } & Female & 49 & 3.97 & 0.68 & 1.58 & 0.11 \\
\hline & Male & 69 & 3.72 & 0.94 & & \\
\hline \multirow[t]{2}{*}{ MBEP } & Female & 49 & 2.55 & 0.52 & -2.48 & $0.01^{* *}$ \\
\hline & Male & 69 & 2.81 & 0.60 & & \\
\hline \multirow[t]{2}{*}{ LFL } & Female & 49 & 2.30 & 0.48 & 0.79 & 0.42 \\
\hline & Male & 69 & 2.19 & 0.95 & & \\
\hline
\end{tabular}




\begin{tabular}{|c|c|c|c|c|c|c|}
\hline & Marital Status & $\mathrm{N}$ & Mean & SD & $\mathrm{t}$ & $\mathrm{P}$ \\
\hline \multirow[t]{2}{*}{ TRFL } & Married & 43 & 3.63 & 0.75 & -0.08 & 0.93 \\
\hline & Single & 75 & 3.64 & 0.75 & & \\
\hline \multirow{2}{*}{ TRAL } & Married & 43 & 3.15 & 0.44 & 0.88 & 0.37 \\
\hline & Single & 75 & 3.08 & 0.38 & & \\
\hline \multirow[t]{2}{*}{ CII } & Married & 43 & 3.79 & 0.78 & 0.86 & 0.38 \\
\hline & Single & 75 & 3.65 & 0.82 & & \\
\hline \multirow[t]{2}{*}{$\mathrm{IM}$} & Married & 43 & 3.70 & 0.83 & 0.21 & 0.82 \\
\hline & Single & 75 & 3.67 & 0.89 & & \\
\hline \multirow[t]{2}{*}{ IC } & Married & 43 & 3.31 & 0.87 & -1.76 & 0.08 \\
\hline & Single & 75 & 3.60 & 0.82 & & \\
\hline \multirow[t]{2}{*}{ IL } & Married & 43 & 3.54 & 0.86 & -0.53 & 0.59 \\
\hline & Single & 75 & 3.62 & 0.77 & & \\
\hline \multirow[t]{2}{*}{ CR } & Married & 43 & 3.76 & 0.86 & 1.22 & 0.22 \\
\hline & Single & 75 & 3.58 & 0.71 & & \\
\hline \multirow[t]{2}{*}{ MBEA } & Married & 43 & 3.87 & 0.86 & 0.37 & 0.70 \\
\hline & Single & 75 & 3.81 & 0.85 & & \\
\hline \multirow[t]{2}{*}{ МBEP } & Married & 43 & 2.70 & 0.64 & 0.53 & 0.95 \\
\hline & Single & 75 & 2.70 & 0.54 & & \\
\hline \multirow[t]{2}{*}{ LFL } & Married & 43 & 2.26 & 0.80 & 0.18 & 0.85 \\
\hline & Single & 75 & 2.23 & 0.79 & & \\
\hline
\end{tabular}

${ }^{*} \mathrm{p}<0.05 ;{ }^{* *} \mathrm{p}<0.01$

Table 5. Values of multiple regression analysis of the dependable variable, MBEP which is the subdimension of Multifactor Leadership Scale.

\begin{tabular}{lcccccc}
\hline Model & $\mathrm{B}$ & $\mathrm{t}$ & $\mathrm{Sig}$ & $\mathrm{F}$ & $\mathrm{p}$ & $\mathrm{R}$ \\
\hline & & & & & & \\
(Constant) & 1.69 & 3.82 & 0.00 & 4.03 & 0.00 & 0.12 \\
Educational & 0.22 & 2.98 & $0.00^{*}$ & & & \\
Age & -0.04 & -1.04 & 0.29 & & & \\
Gender & 0.32 & 3.08 & $0.00^{*}$ & & \\
Marital Status & -0.01 & -0.10 & 0.91 & & &
\end{tabular}

a. Dependent Variable: MBEP df:4.166

Table 6. Rates of multiple regression analysis of the dependent variable, Contingent Reward (CR) which is the sub-dimension of Multifactor Leadership Scale.

\begin{tabular}{lcccccc}
\hline Model & $\mathrm{B}$ & $\mathrm{t}$ & Sig. & $\mathrm{F}$ & $\mathrm{p}$ & $\mathrm{R}$ \\
\hline & & & & & & \\
(Constant) & 5.54 & 9.23 & 0.00 & 2.57 & 0.04 & 0.28 \\
Educational & -0.22 & -2.16 & $0.03^{*}$ & & & \\
Age & -0.07 & -1.27 & 0.20 & & & \\
Gender & -0.26 & -1.83 & 0.07 & & \\
Marital Status & -0.36 & -2.10 & $0.03^{*}$ & &
\end{tabular}

a. Dependent Variable: $\mathrm{CR}$, df:4.113

\section{DISCUSSION}

The purpose of this research was to determine the leadership characteristics of the volunteers in search and rescue organizations. It is considered that there are remarkable differences between the characteristics of volunteers and professionals. The use of volunteers in this research is significant so as to be able to make generalizations. Professional staff operates through a hierarchical order and assignments are made from different departments. Therefore, volunteers could be considered more appropriate for the objectives. Leadership is an important concern for rescue operations. Many mountaineers involved in rescue operations should have management skills. The occasions in which rescuers feel the necessity for an experienced leader to guide them indicate the importance of leadership (23).

When educational variables of the participants are considered (Table 2) a meaningful relationship with inspirational motivation, a component of transactional leadership, stands out $(p<0.01)$.The post graduates $(62.7 \%)$ mentioned inspirational motivation of a leader as a significant factor. It is important for a leader to motivate the team. Hapgood (11) pointed out strong arguments about employing volunteer leaders more effectively. In this research it is pointed out that volunteers are more inclined to teamwork. Gürer (9) has mentioned about inspirational motivation and stated that motivation is a significant leadership characteristic. These outcomes are compatible with the research. There is a remarkable relationship between 
individualized consideration and educational status $(p<0.05)$. One of the outcomes is the need for an experienced leader. Gürer (9) also mentioned that "field control" in his study is related to search and rescue operations. He emphasized knowledge and experience as important features of leadership. An experienced leader creates an environment of confidence. Priest \& Dixon (22) stated the importance of individual competency of outdoor leaders in their research. Leadership skills are integrated with emergency management leadership. These skills provide leaders to gain respect and to be a role model for others (7). This approach supports our conclusion about the individualized consideration. Martin et al. (18) attached considerable attention to the issues like expertise and awareness of limits which are among the eight competency factors considered to be necessary for the outdoor leaders.

Moreover, being aware of the situations that require expertise and a good understanding of leadership are considered as fundamental issues. Individualized consideration can be evaluated within the scope of expertise. Individualized consideration is an important leadership characteristic and other studies mentioned above seem to confirm our argument. In Table 2, it is clearly seen that the average of the responses concerning management-by-exception (passive) and laissez-faire leadership, which are the characteristics of transactional leadership, is low. Although statistical outcomes indicate a slight difference, the participants do not prefer a passive leader. Priest \& Gass (1997) mentioned about the necessary qualifications of an effective leader. According to them, a leader must be a good trainer with technical knowledge, must be aware of security and environmental issues and must have problem solving and decision making skills. The leader also should possess the ability to communicate with team members (8). As laissez-faire leadership ratings are quite low, it may be concluded that the leader should not let the members behave freely, but direct them when it is necessary.

As reported in Table 3, the results about the gender variable of the participants are related with the "management-by-exception passive" dimension of transactional leadership $(\mathrm{p}<0.01)$. It is concluded that male participants $(X=2.81)(t=-2.48)$ are much more effective in this sub-dimension of transactional leadership. This significant difference indicates that acting in a passive manner is not quite effective. As seen in Table 3, the responses concerning "management-by-exception active" are high-rated. In his study Lois (17) concluded that male participants are more experienced than female ones and gender variables of search and rescue volunteers could be examined in this respect.

Furthermore, he mentioned that male participants feel much more comfortable in the current environment. There are various management and leadership styles in search and rescue operations. Knapp stated that a balanced leader should be competent in both simple and difficult skills (24). Management-by-exception active, one of the dimensions of transactional leadership, can be categorized within capability factor. Fulfilment of leadership roles is directly related to the skills of the leaders. The improvement of leadership characteristics depends on experiences rather than abilities. These abilities are referred as technical, personal and expertise capabilities (15). Some researchers have studied leadership behaviours in terms of psychology. They mentioned to the leaders that are considerate and good at orienting the members, exchanging information and taking initiative and also emphasized the issues such as, management, decision making, strategy, system and structure (13). From this point of view, our research is subject to interpretation. When gender variable is considered, the average of the responses is low about the management-byexception passive and laisses-faire leadership dimensions of transactional leadership. In this case, no matter what the gender is, the participants do not prefer a passive leader. They demand a guiding and dominating one.

As it is mentioned in Table 4, there is no significant difference among the components related to marital status variable. Hence, marital status of the participants does not affect leadership characteristics. Distribution has a homogeneous structure in this variable. The average of the responses are high concerning the components of transactional leadership such as charisma, idealized influence, inspirational motivation and individualized consideration. Though there is no remarkable difference in this case, leaders perform a high level of motivation and interest according to the marital status of the participants. Gürer (9) in his research has pointed out that motivation and knowledge are essential characteristics of leadership. When Table IV is analysed, the responses about management-by-exception active 
and management-by-exception passive dimensions are observed to be low. The respondents agree with the arguments on transactional leadership behaviours in a moderate extent. When transactional leadership is analysed due to marital status, management-by-exception passive and management-by-exception active are found to have no effect on AKUT's organizational structure.

The level of MBEP which is a sub-dimension of Multifactor Leadership Scale is clarified as $(\mathrm{R}=0.12)$ $12 \%$ by educational level, age, gender, and marital status variables which are independent variables. The relationship between these referring variables is: $\mathrm{F}(4.166)=4.03, \mathrm{p}<0.01$. At the same time, according to Table 5, the variables which have the greatest impact on ' management by exception passive (MBEP)' are gender $(B=0.32)$ and educational level $(B=0.22)$. It is observed that age and marital status variables have no significant impact on 'management by exception passive (Table 5).

The level of 'Contingent Reward' which is a sub-dimension of Multifactor Leadership Scale (MLQ) is clarified as ( $R=0.28) \% 28$ by educational level, age, gender, and marital status variables which are independent variables. Formulating the relationship between these referring variables: $\mathrm{F}(4.113)=2.57, \mathrm{p}<0.01$. At the same time, according to Table 6 , the variables which have the greatest impact on ' Contingent Reward ' are educational level $(B=-$ $0.22)$ and marital status $(B=-0.36)$. It is observed that age and gender variables have no significant impact on 'Contingent Reward' (Table 6). According to the educational level, intellectual stimulation and individual knowledge has created differences. Hence, it's not wrong to say that leader is an aspect of motivation. Leaders with higher level of education encourage more. This leads to increase in loyalty and respect for the leader. When it is considered that search and rescue has a vital importance, the trust for the leader cannot be ignored. The emergence of related individual knowledge can be associated with expertise. People who are experts in their fields lead in AKUT Search and Rescue Organization. Chandler's (3) survey applied to leaders mentions that education; knowledge, preparedness, listening and adjudication skills are important features. In our research individual knowledge is one of the outstanding features. The differences in leadership are all about to what extent the people are pioneer leaders. It can be associated with experience that the people with high educational level emphasize that personal knowledge, implicitly the field of expertise is more important. Men use passive dimension of management more often. This may be due to the lack of female leaders in AKUT Search and Rescue Organization. Hence it can be concluded that men are more interested and lead more often in search and rescue operations. Examining leadership qualities will make much more contribution to the literature. Observing the disasters and accidents in the world, each operation follows a complex chain of events itself. This case shows us that each event requires a different leadership model. In our study, the lack of decisive or prominent feature of leadership can be associated with the fact that population of this study attend many different operations. Differences between leadership in search operations and rescue operations are expected because the risk is greater in rescue operations. Thus, the leadership qualities will be different.

Consequently, search and rescue leaders should meet the required qualifications. Hapgood (11) in his study stated that volunteer leaders must have high performance standards. In this research which is carried out with volunteers, remarkable results emerged when inspirational motivation, individualized consideration and educational status of the leader were considered. When gender variable is evaluated, management-by-exception passive dimension seems to be noteworthy because of the high rated responses about management-byexception active dimension. In the research, marital status appears to have no effect on leadership characteristics. This situation can be explained by the productive performances of male and female leaders. The leaders are required to motivate the members mentally and increase the level of motivation. An advanced level of individualized consideration of the leader is mentioned as an important fact by the participants. Accordingly, such a leader will provide confidence among the members. A passive management style is not acceptable while an active and motivating leader is recommended. A very decisive leadership quality has taken over in the study. Situational conditions may affect behaviours considering the qualities of people who lead search and rescue operations. Although different researchers reach different results, there is not sufficient research on search and rescue leaders. This research intends to lead other researches and make a contribution to different research areas. As it could be seen in the results, transformational leadership is the most accepted view. Participants consider the transformational 
leadership behaviours more preferable. Considering the situational approach, the leader-member relationship is an important factor in transformational leadership behaviours. In situational leadership, a leadership style based on the current terms of the situation is followed. Although there is an autocratic structure in search and rescue, a good leader-member relationship is thought to provide certain advantages.

\section{REFERENCES}

1. Bass BM, Avolio BJ. MLQ for Researchers, Available from, http://www.mindgarden.com/productsmlqr.htm. 2006.

2. Brymer E, Gray T, Cotton W, Carpenter C. Profiling outdoor leadership. Journal of Outdoor Recreation, Education and Leadership, 2010; 2(1): 93-108.

3. Chandler RC. The marks of a leader., Contingency Planning and Management Magazine, 2001; 6(5): 20-22

4. Deluga RJ, Perry JT. The relationship of subordinate upward influencing behaviour, satisfaction and perceived superior effectiveness with leader-member exchanges. Journal of Occupational Psychology, 1991; 64: 239-252.

5. Demir H, Okan T. Transactional and transformational leadership: an attempt to develop a scale. Management, 2008; 19(61): 72-90.

6. Erçetin ŞŞ. Leader in Spiral Vision (Expanded 2nd Edition). Ankara. Nobel Publications, 2000.

7. Emergency Management Australia. Leadership: Skills for Emergency Services Personel. Australian Emergency Manual Series, 2002; 32: 14-25.

8. Gray T, Brymer E. Effective leadership: Transformational or transactional. Australian Journal of Outdoor Education, 2006; 10(2): 13-19.

9. Gürer B. Investigating the leadership skills in outdoor sports \& search and rescue. Doctoral Thesis, Abant İzet Baysal University, Bolu, 2012.

10. Hardy L. Psychological Skills in Climbing. Fyffe, A. and Peter, I. (eds.) Cambridge: Pelham Books, 1995.

11. Hapgood N. Grow your own: Developing the resource that is the volunteer outdoor leader. Horizons, 2008; 43: 16-19.

12. International Aeronautical and Maritime Search and Rescue. Organization and Managament: Search and Rescue, 2008; (1): 24-57.

13. Kaiser RB, Overfield DV. The leadership value chain. The Psychologist-Manager Journal, 2010; (13): 164-183.
14. Kalkan A. Outdoor recreation, reasons for individuals participation in nature-based sports within the province of Antalya, Master Thesis, Institute of Social Sciences, Akdeniz University, Antalya, 2012.

15. Karslı MD. Strategic Leadership Skills. 21. Century Leadership Symposium, 1997; 1-7, İstanbul.

16. Kaygisız EG. A study about the roles of transformational leadership on creating organizational wisdom. Doctoral Thesis, Institute of Social Sciences, Selçuk University, Konya, 2013.

17. Lois J. Heroic Efforts: The Emotional Culture of Search and Rescue Volunteers, 2003; New York, London.

18. Martin B, Cashel C, Wagstaff M, Breunig M. Outdoor leadership, theory and practice, 2006; Human Kinetics.

19. Mengüç B, Auh S, Shih E. Transformational leadership and market orientation: implications for the implementation of competitive strategies and business unit performance. Journal of Business Research, 2007; 60(4):314-321.

20. National Search and Rescue Committee. Catastrophic incident search and rescue addendum to the national search and rescue: National Search and Rescue, 2008; Washington.

21. Northouse P. Leadership: Theory and Practice. Çev: Cengiz Şimsek. 2013; Sage Publications. 6th. USA

22. Priest S, Dixon T. Toward a new theory of outdoor leadership style. Leisure Studies, 1991; 10(2):163-170(8).

23. Shimanski C. Search and Rescue for Outdoor Leaders. 2008; p. 2-18.

24. Shooter W, Sibthorp J, Paisley K. Outdoor leadership skills: A program perspective. Journal of Experiential Education, 2009; 32(1): 1-13.

25. Tracey JB, Hinkin TR. Transformational Leadership or Effective Managerial Practices? Group \& Organization Management, 1998; 23(3): 220-236.

26. Ülker İ. Mountain Tourism. Ankara. 1992.

27. Yavuz E. An analysis on the effects of transformational leadership and transactional leadership behaviours on organizational commitment, Doctoral Thesis. Institute of Education Sciences, Gazi University, Ankara, 2008.

28. Wisner B, Adams J. Environmental Health in Emergencies and Disasters: Preparedness and Planning. 2002; p. 34.

29. Wu GJ, Chang Y. Outdoor risk management training tool: The development of critical adventure scenario exercise, Proceedings National Conference on Outdoor Leadership, 2010; 17-20. 